\title{
Breath analysis by gas chromatography-mass spectrometry and electronic nose to screen for pleural mesothelioma: a cross- sectional case-control study
}

\author{
Kevin Lamote ${ }^{1,2}$, Paul Brinkman ${ }^{3}$, Lore Vandermeersch ${ }^{4}$, Matthijs Vynck ${ }^{5}$, Peter J. \\ Sterk $^{3}$, Herman Van Langenhove ${ }^{4}$, Olivier Thas $^{5}$, Joris Van Cleemput ${ }^{6}$, Kristiaan \\ Nackaerts ${ }^{7}$ and Jan P. van Meerbeeck ${ }^{2,8}$ \\ ${ }^{1}$ Department of Respiratory Medicine, Ghent University Hospital, Ghent, Belgium \\ ${ }^{2}$ Department of Internal Medicine, Ghent University, Ghent, Belgium \\ ${ }^{3}$ Department of Respiratory Medicine, Academic Medical Centre, University of Amsterdam, Amsterdam, The Netherlands \\ ${ }^{4}$ Department of Sustainable Organic Chemistry and Technology, EnVOC Research Group, Ghent University, Ghent, Belgium \\ ${ }^{5}$ Department of Mathematical Modelling, Statistics and Bio-Informatics, Ghent University, Ghent, Belgium \\ ${ }^{6}$ Occupational Health Service, Eternit N.V., Kapelle-op-den-Bos, Belgium \\ ${ }^{7}$ Department of Respiratory Diseases, KU Leuven, University Hospitals Leuven, Leuven, Belgium \\ ${ }^{8}$ Thoracic Oncology/MOCA, Antwerp University Hospital, Edegem, Belgium \\ Correspondence to: Kevin Lamote, email: kevin.lamote@ugent.be \\ Keywords: mesothelioma, breath tests, volatile organic compounds, gas chromatography-mass spectrometry, electronic nose \\ Received: October 25, $2016 \quad$ Accepted: July 16, $2017 \quad$ Published: September 27, 2017 \\ Copyright: Lamote et al. This is an open-access article distributed under the terms of the Creative Commons Attribution License \\ 3.0 (CC BY 3.0), which permits unrestricted use, distribution, and reproduction in any medium, provided the original author and \\ source are credited.
}

\section{ABSTRACT}

Rationale: Malignant pleural mesothelioma (MPM) is mainly caused by previous exposure to asbestos fibers and has a poor prognosis. Due to a long latency period between exposure and diagnosis, MPM incidence is expected to peak between 2020-2025. Screening of asbestos-exposed individuals is believed to improve early detection and hence, MPM management. Recent developments focus on breath analysis for screening since breath contains volatile organic compounds (VOCs) which reflect the cell's metabolism.

Objectives: The goal of this cross-sectional, case-control study is to identify vocs in exhaled breath of MPM patients with gas chromatography-mass spectrometry (GCMS) and to assess breath analysis to screen for MPM using an electronic nose (eNose).

Methods: Breath and background samples were taken from 64 subjects: 16 healthy controls (HC), 19 asymptomatic former asbestos-exposed (AEX) individuals, 15 patients with benign asbestos-related diseases (ARD) and 14 MPM patients. Samples were analyzed with both GC-MS and eNose.

Results: Using GC-MS, AEx individuals were discriminated from MPM patients with $\mathbf{9 7 \%}$ accuracy, with diethyl ether, limonene, nonanal, methylcyclopentane and cyclohexane as important VOCs. This was validated by eNose analysis. MPM patients were discriminated from AEx+ARD participants by GC-MS and eNose with $94 \%$ and $74 \%$ accuracy, respectively. The sensitivity, specificity, positive and negative predictive values were $100 \%, 91 \%, 82 \%, 100 \%$ for GC-MS and $82 \%, 55 \%, 82 \%$, $55 \%$ for eNose, respectively.

Conclusion: This study shows accurate discrimination of patients with MPM from asymptomatic asbestos-exposed persons at risk by GC-MS and eNose analysis of exhaled VOCs and provides proof-of-principle of breath analysis for MPM screening. 


\section{INTRODUCTION}

Malignant pleural mesothelioma (MPM) is an aggressive tumor originating from the pleural lining of the thorax and is causally associated with previous asbestos exposure $[1,2]$. Despite a ban on asbestos use in the entire European Union in 2005, asbestos is still being produced and consumed in several countries in need for industrial growth. Together with a long average latency period of 40-50 years between first asbestos exposure and MPM diagnosis, this indicates that MPM incidence will further increase [3]. With a 5-year survival rate below $5 \%$, prognosis remains poor, stressing the need for an earlier diagnosis by screening. Serum biomarkers have not proven to be useful for the screening and diagnosis of MPM $[4,5]$. Therefore, recent research focused on breath analysis [6]. Breath contains volatile organic compounds (VOCs) which arise from the body's (patho)physiological processes and have demonstrated to be useful in the detection of asthma, COPD, and tumors [7-12].

Asbestos fibers are known to initiate oxidative stress at the mesothelium [13], inducing lipid peroxidation of the mesothelial cell wall, releasing VOCs, and mutagenic DNA lesions. Furthermore, asbestos fibers activate the NF$\kappa \mathrm{B}$ pathway and promote cell survival which contributes to MPM development [14]. VOCs enter the bloodstream, are transported to the lungs where they enter the alveoli through the gas exchange mechanisms and finally are exhaled. Few studies have addressed the use of VOCs for MPM detection. One study analyzed breath samples from 13 MPM patients, 13 occupationally asbestosexposed persons, and 13 healthy non-exposed controls using gas chromatography-mass spectrometry (GC-MS) [15]. Cyclohexane allowed to discriminate MPM patients with $97.4 \%$ accuracy. Two studies used pattern recognition of exhaled VOCs by cross-reactive sensor technology (electronic nose: eNose) to compare breath samples of the same 3 groups. Dragonieri et al. [16] and Chapman et al. [17] distinguished MPM patients from controls with $92.3 \%$ and $90 \%$ sensitivity, respectively. Recently, our research group was able to discriminate 23 MPM patients from 22 asymptomatic occupationally asbestosexposed persons and 21 healthy non-exposed controls with $87 \%$ sensitivity and $70 \%$ specificity using multicapillary column-ion mobility spectrometry (MCC/IMS) [18]. Nevertheless, these studies have not been replicated nor has GC-MS been directly validated against eNose.

Since MPM is linked to asbestos exposure and oxidative stress, we hypothesize that VOCs and VOC patterns will differ between MPM patients, persons occupationally exposed to asbestos, and those unexposed. To that end, we aimed to identify discriminating VOCs by GC-MS and assess the between-group comparisons with eNose in order to provide the proof-of-principle of screening for MPM by breath analysis.

\section{RESULTS}

\section{Patient characteristics}

Sixty-four participants were included: 14 treatmentnaïve MPM patients, 15 patients with benign asbestosrelated diseases (ARD), 19 AEx persons, and $16 \mathrm{HC}$ individuals (Table 1).

MPM patients were significantly older than the other groups; AEx persons were the youngest. No significant differences were found in smoking status, pack years or BMI between the groups although we observed a trend with AEx persons having have more current smokers. Among the ARD patients, 14 (93\%) had pleural plaques and $1(7 \%)$ had asbestosis.

\section{GC-MS analysis}

In total, 14 MPM patients, 19 AEx subjects, $15 \mathrm{ARD}$ patients and $14 \mathrm{HC}$ controls gave a breath sample for GCMS analysis. We analyzed 5 different models (Table 2, Figure 1): MPM vs. HC (model 1), MPM vs. AEx (model 2), MPM vs. ARD (model 3), MPM vs. AEx+ARD (model 4) and ARD vs. AEx (model 5). Model 1 showed a diagnostic accuracy of $71 \%(52.9 \%-85.7 \%)$. The $\mathrm{AUC}_{\mathrm{ROC}}$ was 0.770 .

Since asbestos-exposed individuals can have a lifetime risk of MPM up to $10 \%$, [13] we examined if it was possible to discriminate AEx and ARD participants from MPM patients in view of using it as screening tool (models 2-4). Discriminating MPM from AEx persons was possible with 97\% accuracy (86.0\%-99.8\%), 93\% sensitivity, $100 \%$ specificity, $100 \%$ PPV, and $95 \%$ NPV. The $\mathrm{AUC}_{\mathrm{ROC}}$ was 0.989 . Discriminating MPM from ARD patients was possible with $79 \%$ accuracy $(61.9 \%-91.2 \%)$, $79 \%$ sensitivity, $80 \%$ specificity, $79 \%$ PPV, and $80 \%$ NPV. The $\mathrm{AUC}_{\mathrm{ROC}}$ was 0.838 . By pooling ARD and AEx persons, we could discriminate MPM patients with 94\% accuracy (84.0\%-98.4\%), 100\% sensitivity, 91\% specificity, $82 \%$ PPV, and $100 \%$ NPV. The $\mathrm{AUC}_{\mathrm{ROC}}$ was 0.943 .

The most frequently selected VOCs in these discriminations were diethyl ether, limonene, cyclohexane, nonanal, VOC $\mathrm{I}_{K} 1287$ and isothiocyanatocyclohexane (Table 2, Supplementary Figures 1-2).

As negative control analysis, we tried to discriminate ARD patients from AEx persons (model 5). This was not possible, showing $50 \%$ accuracy $(33.6 \%-66.4 \%)$ and an $\mathrm{AUC}_{\mathrm{ROC}}$ of 0.365 , even when important discriminators from the other models were included.

\section{eNose analysis}

In total, 11 MPM patients, 15 AEx subjects, 12 ARD patients and $12 \mathrm{HC}$ controls gave a breath sample for eNose analysis. We analyzed the same 5 models as with GC-MS analysis (Table 3, Figure 2). We were able 
Table 1: Patient characteristics

\begin{tabular}{|c|c|c|c|c|c|}
\hline & $\mathrm{HC}$ & AEx & ARD & МPM & p-value \\
\hline $\mathbf{N}$ & 16 & 19 & 15 & 14 & \\
\hline \multicolumn{6}{|l|}{ Gender } \\
\hline Male & $15(93.8 \%)$ & $19(100 \%)$ & $14(93.3 \%)$ & $11(78.6 \%)$ & $0.173^{a}$ \\
\hline Female & $1(6.3 \%)$ & $0(0.0 \%)$ & $1(6.7 \%)$ & $3(22.4 \%)$ & \\
\hline Age & $56(52.5-59.4)$ & $50(49.6-53.2)$ & $60(58.3-63.8)$ & $69(65.7-73.6)$ & $<0.001^{b}$ \\
\hline \multicolumn{6}{|l|}{ Smoke status } \\
\hline Current & $0(0.0 \%)$ & $6(31.6 \%)$ & $1(6.7 \%)$ & $1(7.1 \%)$ & \\
\hline$E X$ & $8(50.0 \%)$ & $7(36.8 \%)$ & $5(33.3 \%)$ & $9(64.3 \%)$ & $0.079^{a}$ \\
\hline Never & $8(50.0 \%)$ & $6(31.6 \%)$ & $9(60.0 \%)$ & $4(28.6 \%)$ & \\
\hline Pack years & $0.3(0.0-6.1)$ & $9.0(0.0-36.0)$ & $0(0.0-10.5)$ & $7(0.0-30.0)$ & $0.106^{b}$ \\
\hline BMI $\left(\mathrm{kg} / \mathrm{m}^{2}\right)$ & $27(23.4-29.3)$ & $27(25.4-28.4)$ & $27(24.5-32.8)$ & $26(23.9-27.1)$ & $0.529^{b}$ \\
\hline
\end{tabular}

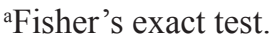

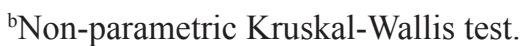

AEx: asymptomatic former asbestos-exposed controls. ARD: patients with benign asbestos related diseases. BMI: body mass index. HC: healthy controls. MPM: malignant pleural mesothelioma.

to discriminate MPM patients from HC controls (model 1) with $65 \%$ accuracy $(44.5 \%-82.3 \%)$. The $\mathrm{AUC}_{\mathrm{ROC}}$ was 0.667. Discriminating MPM from AEx persons was possible with 73\% accuracy (53.9\%-87.4\%), 80\% sensitivity, 64\% specificity, $75 \% \mathrm{PPV}$, and $70 \% \mathrm{NPV}$. The $\mathrm{AUC}_{\mathrm{ROC}}$ was 0.655 .

MPM patients could be discriminated from ARD patients with 70\% accuracy (48.9\%-85.6\%), 75\% sensitivity, 64\% specificity, 69\% PPV, and 70\% NPV. The $\mathrm{AUC}_{\mathrm{ROC}}$ was 0.758 . When ARD and AEx persons were pooled, we could discriminate MPM patients with 74\% accuracy (58.1\%-85.8\%), 82\% sensitivity, 55\% specificity, $82 \%$ PPV, and 55\% NPV. The $\mathrm{AUC}_{\mathrm{ROC}}$ was 0.747 .

Again, it was not possible to discriminate AEx persons from ARD patients, showing 52\% accuracy (33.4\%-70.0\%) and an $\mathrm{AUC}_{\mathrm{ROC}}$ of 0.550 .

\section{DISCUSSION}

In this cross-sectional study, breath analysis by GC-MS allows to discriminate with acceptable accuracy mesothelioma patients from healthy controls, patients with benign asbestos-related diseases, and asymptomatic individuals occupationally exposed to asbestos fibers in the past. This was replicated with an eNose. To our knowledge, this is the first time these discriminations are shown using multiple control groups and taking samples in parallel for GC-MS analysis and eNose replication by using previously validated methods [12]. Considering that occupationally asbestos-exposed persons have a lifetime increased risk for MPM and the latter is a lethal condition with a late-onset development, early detection is of utter importance to improve the disease's management. Therefore, we examined whether it was possible to discriminate MPM patients from AEx and ARD persons. By GC-MS, we discriminated MPM from AEx and ARD persons with $97 \%$ and $79 \%$ accuracy, respectively. When both groups were pooled, the accuracy was 94\%. Given the large sensitivity and NPV of these findings, the present study underlines the capacity of breath analysis as screening tool for persons at risk for MPM.

The most important VOCs selected in all of these GC-MS discriminations are nonanal, diethyl ether, limonene, methylcyclopentane, cyclohexane, a VOC with $I_{K}$ 1287, and isothiocyanatocyclohexane. Furthermore, AEx persons were not easily discriminated from ARD patients, even when including the VOCs that discriminated MPM from the at risk groups, serving as negative controls. This underlines their importance as breath biomarkers for the presence of MPM.

Our results confirm and extend the findings from previous studies [15-19]. Using GC-MS, de Gennaro et al. discriminated 13 MPM patients from $13 \mathrm{HC}$ controls and 13 AEx persons with $97.4 \%$ accuracy using cyclopentane, cyclohexane, dodecane, dimethyl nonane, limonene and $\beta$-pinene [15]. The group showed cyclohexane to be an important MPM marker and cyclopentane as marker for asbestos-exposure. We also found cyclohexane and limonene to be important in the discrimination of MPM from AEx patients and $\beta$-pinene to discriminate ARD from MPM patients. Furthermore, we found diethyl ether and nonanal important discriminators of MPM from AEx and/or ARD patients. These compounds are also found discriminative for lung cancer and are likely 
Table 2: Model characteristics from GC-MS data

\begin{tabular}{|c|c|c|c|c|c|}
\hline \multirow[b]{2}{*}{$\begin{array}{l}\text { Cases vs } \\
\text { controls }\end{array}$} & Model 1 & Model 2 & Model 3 & Model 4 & Model 5 \\
\hline & MPM vs HC & $M P M$ vs $A E x$ & $M P M$ vs $A R D$ & $M P M$ vs $A E x+A R D$ & $A E x$ vs $A R D$ \\
\hline$N$ & 14 vs 14 & 14 vs 19 & 14 vs 15 & 14 vs 34 & 19 vs 15 \\
\hline Sensitivity & $64.3 \%(37.6 \%-85.6 \%)$ & $92.9 \%(69.5 \%-99.6 \%)$ & $78.6 \%(52.1 \%-94.2 \%)$ & $100 \%(80.7 \%-100 \%)$ & $60.0 \%(34.6 \%-81.9 \%)$ \\
\hline Specificity & $78.6 \%(52.1 \%-94.2 \%)$ & $100 \%(85.4 \%-100 \%)$ & $80.0 \%(54.7 \%-94.6 \%)$ & $91.2 \%(77.9 \%-97.7 \%)$ & $42.1 \%(21.9 \%-64.6 \%)$ \\
\hline PPV & $75.0 \%(45.9 \%-93.2 \%)$ & $100 \%(79.4 \%-100 \%)$ & $78.6 \%(52.1 \%-94.2 \%)$ & $82.4 \%(59.2 \%-95.3 \%)$ & $45.0 \%(24.7 \%-66.7 \%)$ \\
\hline NPV & $68.8 \%(43.7 \%-87.5 \%)$ & $95.0 \%(77.8 \%-99.7 \%)$ & $80.0 \%(54.7 \%-94.6 \%)$ & $100 \%(90.8 \%-100 \%)$ & $57.1 \%(31.2 \%-80.4 \%)$ \\
\hline Accuracy & $71.4 \%(52.9 \%-85.7 \%)$ & $97.0 \%(86.0 \%-99.8 \%)$ & $79.3 \%(61.9 \%-91.2 \%)$ & $93.8 \%(84.0 \%-98.4 \%)$ & $50.0 \%(33.6 \%-66.4 \%)$ \\
\hline $\mathrm{AUC}_{\mathrm{ROC}}$ & $0.770(0.577-0.923)^{\#}$ & $0.989(0.955-1.000)^{\#}$ & $0.838(0.671-0.962)^{\#}$ & $0.943(0.866-1.000)^{\#}$ & $0.365(0.435-0.818)$ \\
\hline $\begin{array}{l}\text { VOCs }(\geq 50 \% \\
\text { of times } \\
\text { selected })\end{array}$ & $\begin{array}{l}\text { Nonane } \\
\text { VOC I } I_{K} 1349 \\
\text { Propylbenzene } \\
\text { Benzonitrile } \\
\text { Isoprene } \\
\text { Limonene } \\
\text { 3-methylpentane } \\
\text { 1,3-dichlorobenzene }\end{array}$ & $\begin{array}{l}\text { Ethanol } \\
\text { Diethyl ether } \\
\text { 2-ethyl-1-hexanol } \\
\text { Limonene } \\
\text { Nonanal } \\
\text { 2-methyl-1-propanol } \\
\text { Methylcyclopentane } \\
\text { Cyclohexane } \\
\text { 1,2,4-trichlorobenzene } \\
\text { Naphtalene } \\
\text { VOC I }{ }_{K} 679 \\
\text { Phenol } \\
\text { Chloroform } \\
\text { Linalool } \\
\text { Furfural } \\
\text { VOC I }{ }_{K} 1287 \\
\text { Bromobenzene }\end{array}$ & $\begin{array}{l}\text { VOC I }_{K} 931 \\
\text { VOC I }_{K} 1493 \\
\text { Beta-pinene } \\
\text { Diethyl ether } \\
\text { Limonene } \\
\text { Hexane } \\
\text { 1,2-dichlorobenzene }\end{array}$ & $\begin{array}{l}\text { Ethanol } \\
\text { Diethyl ether } \\
\text { Isothiocyanatocyclohexane } \\
\text { VOC I I }_{K} 1233 \\
\text { VOC I }_{K} 1287 \\
\text { VOC I }_{K} 1309 \\
\text { 1,2-dichlorobenzene } \\
\text { n-Butylbenzene } \\
\text { Methylbenzoate } \\
\text { 1,2,3-trichlorobenzene } \\
\text { Limonene } \\
\text { Bromobenzene } \\
\text { VOC I }{ }_{K} 1100 \\
\text { Tert-butylbenzene } \\
\text { m/p-xylene } \\
\text { 2,2,4-trimethylpentane } \\
\text { Hexamethyldisiloxane } \\
\text { VOC I } I_{K} 1493 \\
\text { VOC I } I_{K} 720\end{array}$ & $\begin{array}{l}\text { Limonene } \\
\text { Isopropyl acetate } \\
\text { 1,3,5-triisopropylbenzene } \\
\text { Diethyl ether } \\
\text { 3,7-dimethyl-3-octanol } \\
\text { Trichloroethylene } \\
\text { Dimethyl disulfide } \\
\text { Ethanol } \\
\text { Phenol } \\
\text { Acetophenone } \\
\text { 2-methyl-1-propanol } \\
\text { 1-butanol } \\
\text { Naphtalene } \\
\text { VOC } I_{K} 615 \\
\text { 1-methylthio-1-propene } \\
\text { Isothiocyanatocyclohexane } \\
\text { Isopropyl benzene } \\
\text { VOC } I_{K} 566 \\
\text { VOC } I_{K} 1111 \\
\text { Hexanal } \\
\text { VOC } I_{K} 767 \\
\text { Ethylbenzene } \\
\text { VOC I } 1349 \\
\text { 1,3-dichlorobenzene } \\
\text { Dimethylsulfide } \\
\text { VOC I } 1105 \\
\text { 2-hexanone } \\
\text { VOC } I_{K} 732 \\
\text { Nonane } \\
\text { 3-methylpentane } \\
\text { n-Butylbenzene }\end{array}$ \\
\hline
\end{tabular}

AEx: asymptomatic former asbestos-exposed controls. ARD: patients with benign asbestos related diseases. AUC $\mathrm{ROC}$ : area under the receiver operator characteristic curve. HC: healthy controls. $\mathrm{I}_{K}$ : Kováts retention index. MPM: malignant pleural mesothelioma. NPV: negative predictive value. PPV: positive predictive value. VOC: volatile organic compound. ${ }^{*}: \mathrm{AUC}_{\mathrm{ROC}}$ statistically different from 0.5 .

to be associated with tumorigenesis [20-22]. This adds to the plausibility of the discriminating capacity of these compounds of MPM.

Furthermore, Cakir et al. discriminated ARD patients and $\mathrm{HC}$ controls using ion mobility spectrometry with $99.9 \%$ accuracy, $96 \%$ sensitivity, and 50\% specificity based upon $\alpha$-pinene and 4-ethyltoluol [19]. We did not find these compounds as important discriminators in our models, weakening their importance as markers for ARD.

The GC-MS findings were replicated by pattern recognition of VOCs obtained by the cross-reactive sensors from the eNose. We discriminated MPM patients from $\mathrm{HC}$ controls, AEx persons and ARD patients with $65 \%, 73 \%$, and $70 \%$ accuracy, 67\%, 80\%, and $75 \%$ sensitivity and $64 \%, 64 \%$, and $64 \%$ specificity, respectively. When AEx and ARD patients were pooled, MPM patients were discriminated with 74\% accuracy, $82 \%$ sensitivity and $55 \%$ specificity. The finding that the discriminative capacity by the eNose were somewhat lower as compared to the GC-MS results is due to the smaller number of patients who gave a sample for eNose analysis and the fact that eNoses recognize the bulk of the breath rather than specific individual VOCs.

Although we are reaching the same conclusions, our results slightly differ from those previously reported. Using the Cyranose, Dragonieri et al. discriminated 13 
MPM patients from 13 AEx controls with $92 \%$ sensitivity and $86 \%$ specificity and from $13 \mathrm{HC}$ controls with $92 \%$ sensitivity and 69\% specificity [16]. Furthermore, Chapman et al. discriminated 10 MPM patients from 32 HC controls with $90 \%$ sensitivity and 91\% specificity and from 18 ARD patients with $90 \%$ sensitivity and $83 \%$ specificity [17]. This may not be unexpected because of the lower number of patients and the fact we merged the sensor defections of 4 devices as final eNose profile.

The strength of our study lies in the multiple groups design and the replication of the results between two essentially different technologies for molecular assessment in exhaled air. Nevertheless, we acknowledge our study has important limitations. First of all, the low number of included participants restricts its application in the whole population. However, our results are in line with previous research and stresses its potential as screening tool. Secondly, our patients and controls were not matched for age and a trend in difference in smoking status was found. This can be due to the long latency period between first asbestos-exposure and MPM diagnosis, delaying diagnosis to late stages in more elderly people. Furthermore, it is hard to find healthy controls without substantial comorbidities at matched age. The difference in smoking status can originate from the fact that asbestos workers were blue-collar workers; an industry known to have an increased incidence of smokers [23]. Nevertheless, since MPM development is independent of smoking, the impact of smoking status on our results is expected to be minimal and smoking-associated VOCs (benzene, 2,5-dimethylfuran, and toluene) were not selected in either model, underlining the independency. Thirdly, since this study retrospectively questioned the participants, we cannot exclude potential recall bias and, hence, we have no information about the duration and intensity of asbestos exposure in our patients and controls nor about the time of last exposure on the breath composition. Fourthly, although an inspiratory VOC-filter was used, it is possible that exogenous compounds could have contaminated the breath since inhaled VOCs can be stored for a long time in the body's fat compartments [24], and the sampling and

\section{ROC Curve}

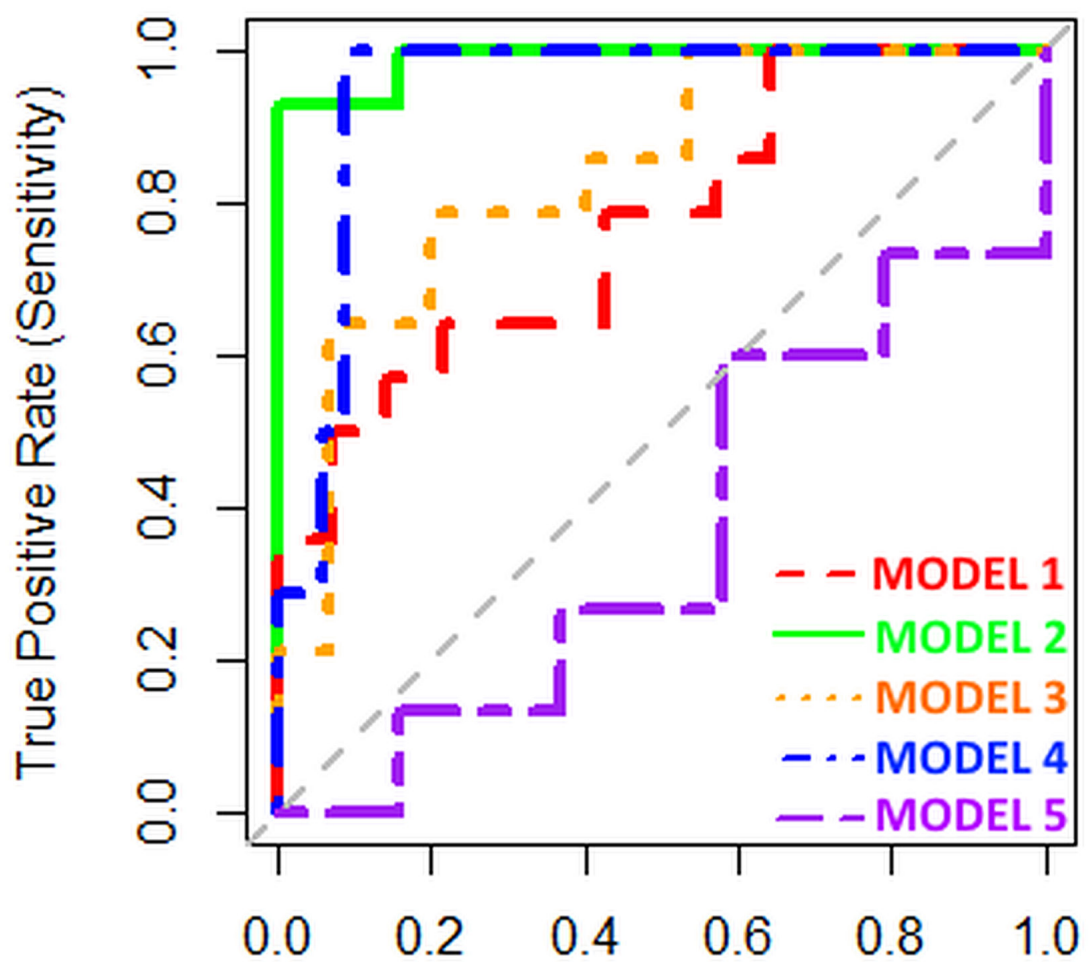

False Positive Rate (1-Specificity)

Figure 1: ROC curves of the different models based upon GC-MS analysis. 
Table 3: Model characteristics from eNose data

\begin{tabular}{|c|c|c|c|c|c|}
\hline & Model 1 & Model 2 & Model 3 & Model 4 & Model 5 \\
\hline $\begin{array}{l}\text { Cases vs } \\
\text { controls }\end{array}$ & MPM & $M P M$ vs $A E x$ & $M P M v S A R D$ & $M P M$ vs $A E x+A R D$ & vs $A R D$ \\
\hline$N$ & 11 vs 12 & $11 v$ & 11 vs 12 & $11 v$ & 15 vs 12 \\
\hline Sensitivity & $66.7 \%(37.7 \%-88.4 \%)$ & $80.0 \%(54.7 \%-94.6 \%)$ & $75.0 \%(45.9 \%-93.2 \%)$ & $81.5 \%(63.7 \%-92.9 \%)$ & $58.3 \%(30.3 \%-82.8 \%)$ \\
\hline Specificity & $63.6 \%(33.7 \%-87.2 \%)$ & $63.6 \%(33.7 \%-87.2 \%)$ & $63.6 \%(33.7 \%-87.2 \%)$ & $54.5 \%(26.0 \%-81.0 \%)$ & $46.7 \%(23.2 \%-71.3 \%)$ \\
\hline PPV & $66.7 \%(37.7 \%-88.4 \%)$ & $75.0 \%(50.1 \%-91.5 \%)$ & $69.2 \%(41.3 \%-89.4 \%)$ & $81.5 \%(63.7 \%-92.9 \%)$ & $46.7 \%(23.2 \%-71.3 \%)$ \\
\hline NPV & $63.6 \%(33.7 \%-87.2 \%)$ & $70.0 \%(38.0 \%-91.7 \%)$ & $70.0 \%(38.0 \%-91.7 \%)$ & $54.5 \%(26.0 \%-81.0 \%)$ & $58.3 \%(30.3 \%-82.8 \%)$ \\
\hline Accuracy & $65.2 \%(44.5 \%-82.3 \%)$ & $73.1 \%(53.9 \%-87.4 \%)$ & $69.6 \%(48.9 \%-85.6 \%)$ & $73.7 \%(58.1 \%-85.8 \%)$ & $51.9 \%(33.4 \%-70.0 \%)$ \\
\hline $\mathrm{AUC}_{\mathrm{ROC}}$ & $0.667(0.434-0.900)$ & $0.655(0.416-0.893)$ & $0.758(0.548-0.967)^{\#}$ & $0.747(0.582-0.913)^{\#}$ & $0.550(0.322-0.778)$ \\
\hline
\end{tabular}

AEx: asymptomatic former asbestos-exposed controls. ARD: patients with benign asbestos related diseases. $\mathrm{AUC}_{\mathrm{ROC}}$ : area under the receiver operator characteristic curve. HC: healthy controls. MPM: malignant pleural mesothelioma. NA: not applicable. NPV: negative predictive value. PPV: positive predictive value. ${ }^{\sharp} \mathrm{AUC}_{\mathrm{ROC}}$ statistically different from 0.5 .

analysis materials used can also release compounds. Finally, despite a cross-sectional, case-control design, our study was not blinded and we took breath samples from participants with known diagnosis. The next step should be to perform a blinded, prospective, casecontrol, cohort study to assess the diagnostic features of the breath test.
Despite these limitations, we found MPM patients to be discriminated from the at risk groups with clinically relevant accuracy by both GC-MS and eNose analysis. The large sensitivity and NPV allows breath analysis to be used as screening tool for exclusion of disease in at risk persons and to enrich the fraction of individuals at risk for further screening. By doing

ROC Curve

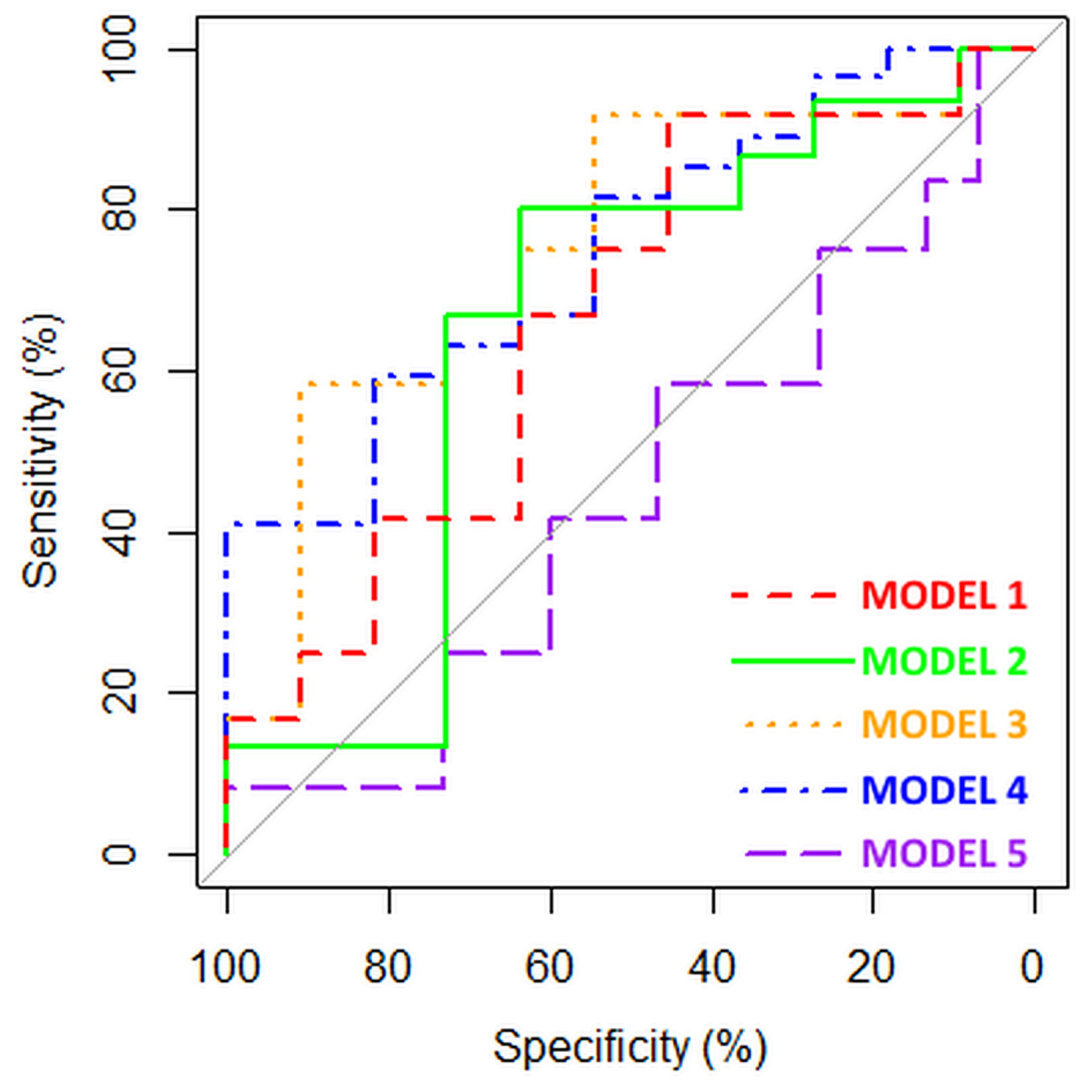

Figure 2: ROC curves of the different models based upon eNose analysis. 
so, not every asbestos-exposed person is subjected to repeated chest imaging procedures, which will help the monitoring of asbestos-exposed individuals to be more cost-effective and reduce the associated radiation exposure [25]. Future research should focus on the next step: validating our results in an independent, large, multicenter series with blinding of the investigator for the underlying disease, monitoring AEx persons over time and see how breath analysis can be used to screen for MPM. In addition, the VOCs should be compared and correlated to mesothelin and linked with the pathophysiology of MPM by comparing the VOCs in breath with those in the headspace of mesothelioma cell lines and pleural fluid. This will ultimately improve the specificity.

\section{MATERIALS AND METHODS}

\section{Study design and participants}

We performed a multicenter, cross-sectional, casecontrol study in 64 subjects. Fourteen MPM patients, fifteen patients with well-defined benign asbestos-related diseases (ARD), and sixteen healthy non-asbestos exposed (HC) controls were recruited in the three participating university hospitals. Nineteen asymptomatic former asbestos-exposed individuals with well-documented asbestos exposure, were recruited via the occupational health service of a Belgian fiber-cement factory that processed asbestos until 1997. Treatment-naïve MPM patients were included after diagnosis, confirmed by the Belgian Mesothelioma Pathology Panel. Exclusion criteria were the start of any anti-tumor treatment before breath sampling, and the presence of non-asbestos-related diseases in the control groups. Before inclusion, a recent CT scan or chest X-ray ( $<12$ months) had to be present to confirm the medical condition. The study was approved by the Institutional Review Board of Ghent University Hospital (LONG 11-01; Belgian registration number B670201111954) and was conducted in accordance with the Helsinki Convention. Participants had to give their written informed consent and two questionnaires had to be completed: one to check if the participants met the inclusion criteria and one to collect data about demographics and past occupational asbestos exposure. For all patients, a detailed medical record had to be available.

\section{Breath sampling}

Breath was sampled using a previously validated method $[8,12]$. In short, participants breathed tidally with a nose clip into a 2-way non-rebreathing valve (Hans Rudolph 2700, Hans Rudolph, Kansas City, USA) with an inspiratory VOC-filter (A2, North Safety, Middelburg, NL) at the inlet side. After 5 minutes of tidal breathing, the participants inhaled maximally and the expiratory port was connected to a 10L Tedlar bag (SKC Inc., Eighty Four, PA, USA). Subsequently, the subjects exhaled a full vital capacity volume into the Tedlar bag which was closed afterwards. Within 10 minutes, the bag was connected to an external pump and $500 \mathrm{ml}$ of the breath sample was loaded onto a sorbent tube (3.5" long, 0.25 " outer diameter) filled with $200 \mathrm{mg}$ Tenax ${ }^{\circledR}$ GR (35/60 mesh; Markes International Ltd., Llantrisant, UK) for GC-MS analysis at a flow rate of $100 \mathrm{ml} . \mathrm{min}^{-1}$ for 5 minutes. Immediately afterwards, $500 \mathrm{ml}$ of the breath sample was loaded onto another Tenax ${ }^{\circledR}$ GR tube (Tenax ${ }^{\circledR}$ GR SS 6mm x 7" (CAMSCO, Houston, Texas, USA)) for eNose analysis at a flow rate of $250 \mathrm{ml} . \mathrm{min}^{-1}$ for 2 minutes. The sampling tubes were tightened, packed in a glass jar, and sent out for central analysis.

\section{Gas chromatography - mass spectrometry (GC- MS) analysis}

Prior to use, the Tenax ${ }^{\circledR}$ GR-tubes were conditioned for 1 hour at $300^{\circ} \mathrm{C}$ while being flushed with helium (50 $\left.\mathrm{ml} \cdot \mathrm{min}^{-1}\right)$. After conditioning but before sampling, the tubes were loaded with $10.7 \mathrm{ng}$ toluene-d8 internal standard, by making a two-phase system and using a home-made injector system. After sampling, breath analytes were desorbed from the Tenax ${ }^{\circledR}$ GR-column using a Unity series 2 Thermal Desorption system (Markes, Llantrisant, UK) by heating the tube to $260^{\circ} \mathrm{C}(10 \mathrm{~min}$ at $\left.20 \mathrm{ml} \cdot \mathrm{min}^{-1}\right)$. Prior to desorption, tubes were dry purged for 4 minutes at $20 \mathrm{ml} \cdot \mathrm{min}^{-1}$. Next, analytes were refocused on a microtrap filled with Tenax ${ }^{\circledR} \mathrm{TA}$, cooled at $-10^{\circ} \mathrm{C}$. After flash-heating the microtrap at $280^{\circ} \mathrm{C}$ for $3 \mathrm{~min}$, analytes were carried by a He-flow (constant pressure: $50 \mathrm{kPa}$ ) and injected with a split-flow of $5 \mathrm{ml} \cdot \mathrm{min}^{-1}$ onto a $30 \mathrm{~m}$ FactorFour VF-1ms low-bleed bounded-phase capillary GC-column (Varian, Sint-Katelijne-Waver, Belgium; $100 \%$ polydimethylsiloxane, internal diameter $0.25 \mathrm{~mm}$, film thickness $1 \mathrm{~mm}$ ). The flow path was heated to $130^{\circ} \mathrm{C}$. The GC (Focus GC, Thermo Finnigan, Milan, Italy) oven temperature was initially set at $35^{\circ} \mathrm{C}$ for and kept for 10 minutes, then heated to $60^{\circ} \mathrm{C}$ at a rate of $2^{\circ} \mathrm{C} \cdot \mathrm{min}^{-}$ 1. Afterwards the temperature was increased to $170^{\circ} \mathrm{C}$ at $8^{\circ} \mathrm{C} \cdot \mathrm{min}^{-1}$ and finally to $240^{\circ} \mathrm{C}\left(\right.$ at $15^{\circ} \mathrm{C} \cdot \mathrm{min}^{-1}$ ), maintained for $10 \mathrm{~min}$. The MS transfer line was heated to $240^{\circ} \mathrm{C}$. The ion source was put at $220^{\circ} \mathrm{C}$. Masses with $\mathrm{m} / \mathrm{z} 29$ to 300 were recorded in full scan mode $(200 \mathrm{~ms} / \mathrm{scan})$ on a DSQII Single Quadrupole MS (Thermo Finnigan, Austin, TX, USA), hyphenated to the GC, and operating at an electron impact energy of $70 \mathrm{eV}$. Chromatograms and mass spectra were processed using XCalibur software (Thermo Finnigan, v2.2) and the NIST database. For unidentified compounds, the Kováts retention index $\left(\mathrm{I}_{K}\right)$ was calculated. 


\section{Electronic nose (eNose) analysis}

Exhaled VOCs were thermally desorbed from Tenax ${ }^{\circledR}$ GR tubes using nitrogen as carrier gas. Next, samples were analyzed by an assembly of four different eNoses, based on deviant sensor technologies: Cyranose C320 [26], Tor Vergata eNose [27], Common Invent eNose [28], and Owlstone Lonestar [29]. When exposed to a gas mixture, the sensors swell, resulting in a change of electrical resistances $(\Delta \mathrm{R})$. The $\Delta \mathrm{R} / \mathrm{R}$-values are stored as raw data, producing a breathprint that describes the VOC mixture which can be used for pattern-recognition algorithms [30, 31]. The final eNose-based breath profiles were established by merging the sensor defections of all four devices.

\section{Statistics}

$\mathrm{R}$ (v3.3.1) using the $\mathrm{R}$ studio interface was used for data analysis. Categorical variables are compared using a Pearson $\mathrm{Chi}^{2}$-test and reported as ratios. For continuous variables, normality was checked by a Shapiro-Wilk test. Dependent on the outcome, variables are given as mean (standard deviation) or median (quartile 1-quartile 3).

The raw eNose data were reduced by principle components analysis into principle components (PC). PCs explaining at least $70 \%$ of variance were retained and subsequently used as independent variables for linear discriminant analysis. The leave-one-out cross-validated (LOOCV) accuracy was reported in order to limit false discoveries. Receiver operating characteristic (ROC) curves were constructed.

For GC-MS data, the high number of variables and the rather low number of samples requires penalized logistic regression using the least absolute shrinkage and selection operator (lasso) to search for VOCs that have the most discriminative power for distinguishing MPM patients from controls. We used the glmnet R-package (v2.0-2) for fitting binomial lasso logistic models. This involves the selection of a tuning parameter $(\lambda)$ that determines the number of selected VOCs. The optimal $\lambda$ is selected by fitting the model for a sequence of $\lambda$-values, and for each of the $\lambda$-values the fitted model is evaluated by estimating the misclassification error rate by LOOCV. The $\lambda$-value minimizing this error rate was selected and used to fit the final model. Using the predicted outcomes of all of the patients, we then constructed an ROC curve (using the ROCR R-package (v1.0-7)) and estimated sensitivity, specificity, positive (PPV) and negative predictive value (NPV), the diagnostic accuracy of the final model, and the area under the curve $\left(\mathrm{AUC}_{\mathrm{ROC}}\right)$ with their $95 \%$ confidence intervals. We furthermore examined the number of times a VOC was selected by the lasso regressions. Variables selected in $>50 \%$ of folds were considered important.

\section{CONCLUSION}

GC-MS and eNose analysis allowed to discriminate MPM persons from asymptomatic, former asbestos-exposed persons at risk for MPM with great accuracy. The VOCs diethyl ether, methylcyclopentane, nonanal, limonene, cyclohexane, VOC $I_{K} 1287$ and isothiocyanatocyclohexane were identified as promising biomarkers for MPM. These data provide the proof-of-principle for future screening of persons at risk for MPM as a step-up tool in its diagnosis, making it less-invasive for the patient.

\section{Author contributions}

KL, JPVM contributed to the conception of the study. JPVM, JVC and KN helped including participants. LV, HV, PB and PJS helped analyzing samples. MV and OT controlled statistics. KL drafted the main manuscript. All authors adjusted and updated the manuscript to its final form and approved this for publication.

\section{CONFLICTS OF INTEREST}

None of the authors declare to have conflicts of interest. This study was presented at the ERS International Congress, 3-7 September 2016, London, UK.

\section{GRANT SUPPORT}

This study was funded by the Belgian Foundation against Cancer (grants STK 2010-205 and STK 2012223 ) and the 'Emmanuel van der Schueren' grant from the Flemish League against Cancer.

\section{REFERENCES}

1. van Meerbeeck JP, Scherpereel A, Surmont VF, Baas P. Malignant pleural mesothelioma: the standard of care and challenges for future management. Crit Rev Oncol Hematol. 2011; 78: 92-111. https://doi.org/10.1016/j. critrevonc.2010.04.004.

2. Schunselaar LM, Quispel-Janssen JM, Neefjes JJ, Baas P. A catalogue of treatment and technologies for malignant pleural mesothelioma. Expert Rev Anticancer Ther. 2016; 16: 455-63. https://doi.org/10.1586/14737140.2016.11621 00 .

3. Neumann V, Loseke S, Nowak D, Herth FJ, Tannapfel A. Malignant pleural mesothelioma: incidence, etiology, diagnosis, treatment, and occupational health. Dtsch Arztebl Int. 2013; 110: 319-26. https://doi.org/10.3238/ arztebl.2013.0319.

4. Hollevoet K, Reitsma JB, Creaney J, Grigoriu BD, Robinson BW, Scherpereel A, Cristaudo A, Pass HI, Nackaerts K, Rodriguez Portal JA, Schneider J, Muley T, Di Serio F, et al. Serum mesothelin for diagnosing 
malignant pleural mesothelioma: an individual patient data meta-analysis. J Clin Oncol. 2012; 30: 1541-9. https://doi. org/10.1200/JCO.2011.39.6671.

5. Pass HI, Levin SM, Harbut MR, Melamed J, Chiriboga L, Donington J, Huflejt M, Carbone M, Chia D, Goodglick L, Goodman GE, Thornquist MD, Liu G, et al. Fibulin-3 as a blood and effusion biomarker for pleural mesothelioma. N Engl J Med. 2012; 367: 1417-27. https://doi.org/10.1056/ NEJMoa1115050.

6. Boots AW, Bos LD, van der Schee MP, van Schooten FJ, Sterk PJ. Exhaled molecular fingerprinting in diagnosis and monitoring: validating volatile promises. Trends Mol Med. 2015; 21: 633-44. https://doi.org/10.1016/j. molmed.2015.08.001.

7. Schleich FN, Dallinga JW, Henket M, Wouters EF, Louis R, Van Schooten FJ. Volatile organic compounds discriminate between eosinophilic and neutrophilic inflammation in vitro. J Breath Res. 2016; 10: 016006. https://doi. org/10.1088/1752-7155/10/1/016006.

8. Dragonieri S, Schot R, Mertens BJ, Le Cessie S, Gauw SA, Spanevello A, Resta O, Willard NP, Vink TJ, Rabe KF, Bel EH, Sterk PJ. An electronic nose in the discrimination of patients with asthma and controls. J Allergy Clin Immunol. 2007; 120: 856-62. https://doi.org/10.1016/j. jaci.2007.05.043.

9. Shafiek H, Fiorentino F, Merino JL, Lopez C, Oliver A, Segura J, de Paul I, Sibila O, Agusti A, Cosio BG. Using the electronic nose to identify airway infection during COPD exacerbations. PLoS One. 2015; 10: e0135199. https://doi. org/10.1371/journal.pone.0135199.

10. Gasparri R, Santonico M, Valentini C, Sedda G, Borri A, Petrella F, Maisonneuve P, Pennazza G, D’Amico A, Di Natale C, Paolesse R, Spaggiari L. Volatile signature for the early diagnosis of lung cancer. J Breath Res. 2016; 10: 016007. https://doi.org/10.1088/1752-7155/10/1/016007.

11. Fu XA, Li M, Knipp RJ, Nantz MH, Bousamra M. Noninvasive detection of lung cancer using exhaled breath. Cancer Med. 2014; 3: 174-81. https://doi.org/10.1002/ cam4.162.

12. Fens N, Roldaan AC, van der Schee MP, Boksem RJ, Zwinderman AH, Bel EH, Sterk PJ. External validation of exhaled breath profiling using an electronic nose in the discrimination of asthma with fixed airways obstruction and chronic obstructive pulmonary disease. Clin Exp Allergy. 2011; 41: 1371-8. https://doi. org/10.1111/j.1365-2222.2011.03800.x.

13. Lamote K, Nackaerts K, van Meerbeeck JP. Strengths, weaknesses, and opportunities of diagnostic breathomics in pleural mesothelioma-a hypothesis. Cancer Epidemiol Biomarkers Prev. 2014; 23: 898-908. https://doi. org/10.1158/1055-9965.EPI-13-0737.

14. Yang H, Rivera Z, Jube S, Nasu M, Bertino P, Goparaju C, Franzoso G, Lotze MT, Krausz T, Pass HI, Bianchi ME, Carbone M. Programmed necrosis induced by asbestos in human mesothelial cells causes high-mobility group box 1 protein release and resultant inflammation. Proc Natl Acad Sci U S A. 2010; 107: 12611-6. https://doi.org/10.1073/ pnas. 1006542107.

15. de Gennaro G, Dragonieri S, Longobardi F, Musti M, Stallone G, Trizio L, Tutino M. Chemical characterization of exhaled breath to differentiate between patients with malignant pleural mesothelioma from subjects with similar professional asbestos exposure. Anal Bioanal Chem. 2010; 398: 3043-50. https://doi.org/10.1007/s00216-010-4238-y.

16. Dragonieri S, van der Schee MP, Massaro T, Schiavulli N, Brinkman P, Pinca A, Carratu P, Spanevello A, Resta O, Musti M, Sterk PJ. An electronic nose distinguishes exhaled breath of patients with malignant pleural mesothelioma from controls. Lung Cancer. 2012; 75: 326-31. https://doi. org/10.1016/j.lungcan.2011.08.009.

17. Chapman EA, Thomas PS, Stone E, Lewis C, Yates DH. A breath test for malignant mesothelioma using an electronic nose. Eur Respir J. 2012; 40: 448-54. https://doi. org/10.1183/09031936.00040911.

18. Lamote $\mathrm{K}$, Vynck $\mathrm{M}$, Van Cleemput $\mathrm{J}$, Thas $\mathrm{O}$, Nackaerts K, van Meerbeeck JP. Detection of malignant pleural mesothelioma in exhaled breath by multicapillary column/ion mobility spectrometry (MCC/ IMS). J Breath Res. 2016; 10: 046001. https://doi. org/10.1088/1752-7155/10/4/046001.

19. Cakir Y, Métrailler L, Baumbach JI, Kraus T. Signals in asbestos related diseases in human breath - preliminary results. Int J Ion Mobil Spectrom. 2014; 17: 87-94. https:// doi.org/10.1007/s12127-014-0147-7.

20. Phillips M, Gleeson K, Hughes JM, Greenberg J, Cataneo RN, Baker L, McVay WP. Volatile organic compounds in breath as markers of lung cancer: a cross-sectional study. Lancet. 1999; 353: 1930-3. https://doi.org/Doi 10.1016/ S0140-6736(98)07552-7.

21. Poli D, Goldoni M, Corradi M, Acampa O, Carbognani P, Internullo E, Casalini A, Mutti A. Determination of aldehydes in exhaled breath of patients with lung cancer by means of on-fiber-derivatisation SPME-GC/MS. J Chromatogr B Analyt Technol Biomed Life Sci. 2010; 878: 2643-51. https://doi.org/10.1016/j.jchromb.2010.01.022.

22. Baumbach JI, Maddula S, Sommerwerck U, Besa V, Kurth I, Bödeker B, Teschler H, Freitag L, Darwiche K. Significant different biomarker during bronchoscopic ion mobility spectrometry investigation of patients suffering lung carcinoma. Int J Ion Mobil Spectrom. 2011; 14: 159-66.

23. Smith DR. Tobacco smoking by occupation in Australia and the United States: a review of national surveys conducted between 1970 and 2005. Ind Health. 2008; 46: 77-89. https://doi.org/10.2486/indhealth.46.77.

24. Kramer C, Mochalski P, Unterkofler K, Agapiou A, Ruzsanyi V, Liedl KR. Prediction of blood:air and fat:air partition coefficients of volatile organic compounds for the interpretation of data in breath gas 
analysis. J Breath Res. 2016; 10: 017103. https://doi. org/10.1088/1752-7155/10/1/017103.

25. Massardier-Pilonchery A, Bergeret A. [Follow-up after occupational asbestos exposure: terms and devices in foreign]. [Article in French]. Rev Mal Respir. 2011; 28: 556-64. https://doi.org/10.1016/j.rmr.2010.08.012.

26. Lewis NS. Comparisons between mammalian and artificial olfaction based on arrays of carbon black-polymer composite vapor detectors. Acc Chem Res. 2004; 37: 66372. https://doi.org/10.1021/ar030120m.

27. Di Natale C, Paolesse R, Damico A. Metalloporphyrins based artificial olfactory receptors. Sens Actuators B Chem. 2007; 121: 238-46. https://doi.org/10.1016/j. snb.2006.09.038.

28. Bos LD, van Walree IC, Kolk AH, Janssen HG, Sterk PJ, Schultz MJ. Alterations in exhaled breath metabolitemixtures in two rat models of lipopolysaccharide-induced lung injury. J Appl Physiol (1985). 2013; 115: 1487-95. https://doi.org/10.1152/japplphysiol.00685.2013.

29. Arasaradnam RP, McFarlane MJ, Ryan-Fisher C, Westenbrink E, Hodges P, Thomas MG, Chambers S, O'Connell N, Bailey C, Harmston C, Nwokolo CU, Bardhan KD, Covington JA. Detection of colorectal cancer (CRC) by urinary volatile organic compound analysis. PLoS One. 2014; 9: e108750. https://doi.org/10.1371/ journal.pone.0108750.

30. Rock F, Barsan N, Weimar U. Electronic nose: current status and future trends. Chem Rev. 2008; 108: 705-25. https://doi.org/10.1021/cr068121q.

31. Leopold JH, Bos LD, Sterk PJ, Schultz MJ, Fens N, Horvath I, Bikov A, Montuschi P, Di Natale C, Yates DH, Abu-Hanna A. Comparison of classification methods in breath analysis by electronic nose. J Breath Res. 2015; 9: 046002. https://doi.org/10.1088/1752-7155/9/4/046002. 